\title{
EDUCAÇÃO AMBIENTAL NA CIDADE DE SOBRAL: DO COTIDIANO A SALA DE AULA ${ }^{1}$
}

\author{
Adelly Cristina ${ }^{2}$ \\ Marcélia Vieira Torres ${ }^{3}$ \\ José Falcão Sobrinho ${ }^{4}$
}

\section{RESUMO}

O presente ensaio ilustra a pesquisa - ação que a comunidade do Colégio Estadual Dom José Tupinambá da Frota, Sobral - CE realizou acerca do meio ambiente na cidade de Sobral. Para tanto, associou - se o cotidiano dos discentes com as abordagens que envolvem a temática, mediante a identificação dos problemas ambientais na respectiva cidade. Ressalta - se que a educação atual, trabalha na perspectiva do local ao global, devido ser de fácil acessibilidade, melhor entendimento e a participação assídua dos envolvidos, pois age em seu convívio. Desta forma, a metodologia adotada promoveu atividades teóricas e práticas (oficinas, palestras, painéis, entre outros) com o intuito de atitudes positivas e comprometimento pessoal com a proteção ambiental através da interdisciplinaridade.

PALAVRAS CHAVES: Educação ambiental. Cidade. Escola.

\section{ENVIRONMENTAL EDUCATION IN SOBRAL CITY: DAILY LIFE OF A CLASSROOM}

\author{
ABSTRACT \\ This test illustrates the research - action that the community of State College Dom José Tupinambá \\ Fleet, Sobral - CE made about the environment in the city of Sobral. There fore, associated - the daily \\ life of students with approaches involving the theme by identifying the environmental problems in their \\ city. It points out - that the current education, works in the local perspective to global, due to be easily

\footnotetext{
$1 \quad$ Projeto desenvolvido na Escola Dom José Tupinambá da Frota, em Sobral/CE.

2 Resultou em uma monografia no curso de Especialização em Desenvolvimento do Semiárido, defendida pela autora. Email: adellycristina@hotmail.com

3 Participou das atividades da pesquisa. Professora da Escola Dom José Tupinambá da Frota, em Sobral e discente do curso de mestrado acadêmico em Geografia da UVA. Email: marcellya.torres@hotmail.com

$4 \quad$ Prof. (orientador) Dr. do Curso de Mestrado Acadêmico em Geografia da Universidade Estadual Vale do Acaraú/UVA. Email: falcao.sobral@gmail.com
} 




accessible, better understanding and the regular participation of those involved, because it acts in its conviviality. Thus, the adopted methodology promoted theoretical and practical activities (workshops, lectures, panels, etc.) in order to positive attitudes and personal commitment to environmental protection through interdisciplinarity.

KEYWORDS: Environmental education. City. School.

\section{EDUCACIÓN AMBIENTAL EN SOBRAL CIUDAD: LA VIDA DIARIA DE UN AULA}

\section{RESUMEN:}

Este ensayo ilustra la investigación - acción que la comunidad de State College Dom José Tupinambá Flota, Sobral - CE hechas por el medio ambiente en la ciudad de Sobral. Por lo tanto, asociado - la vida cotidiana de los estudiantes con los enfoques que involucran el tema mediante la identificación de los problemas ambientales en su ciudad. Recuerda - que la educación actual, que funciona en la perspectiva local a lo global, debe ser fácilmente accesible, mejor comprensión y la participación regular de los involucrados, ya que actúa en su convivencia. Por lo tanto, la metodología adoptada promovió actividades teóricas y prácticas (talleres, conferencias, paneles, etc.) con el fin de actitudes positivas y compromiso personal para la protección del medio ambiente a través de la interdisciplinariedad.

PALABRAS CLAVE: Educación ambiental. Ciudad. Escuela

\section{INTRODUÇÃO}

A crise ambiental e a sobrevivência do planeta têm sido assuntos bastante discutidos na atualidade. Muito tem se dito e escrito sobre educação ambiental como uma necessidade premente da sociedade contemporânea, face às graves consequências ambientais do homem ao uso dos recursos naturais no desenvolvimento das atividades econômicas. O que era comum ouvir falar de degradação ambiental no campo, hoje tomou parte dos discursos nos centros urbanos.

A interação entre os homens e o ambiente ultrapassou a questão da simples sobrevivência, quando se fala na produção de alimentos, mas sim a preocupação com o futuro, e que herança iremos deixar aos nossos descendentes, 
Revista Nacional de

Gerenciamento de Cidades

por isso, se tem falado muito em desenvolvimento sustentável, de forma global e nos mais diferentes espaços.

Com isso, nota - se, a necessidade de disseminar entre crianças e jovens novas atitudes com relação ao cuidado com o planeta que habitamos. Assim, fica evidente a importância de sensibilizar as pessoas para que hajam de modo responsável e com consciência, cuidando do meio ambiente de forma contínua. E é neste contexto, que a escola, se torna uma importante forma de veiculação acerca de ações educativas voltadas às atividades de proteção, recuperação e melhoria socioambiental, além de potencializar a função da educação para as mudanças culturais e sociais, no que concerne a educação ambiental no planejamento estratégico para o desenvolvimento sustentável.

É nessa lógica, que a comunidade escolar do Colégio Estadual Dom José Tupinambá da Frota, inserida no espaço urbano de Sobral, no estado do Ceará, se empenharam a buscar maneiras de cuidar do meio, através da realização de ações práticas, momento em que tal comunidade participou de atividades que remetem tal discussão, ou seja, a problemática ambiental no espaço urbano. Dentro deste contexto, torna - se oportuno, tentar associar o cotidiano dos alunos com as abordagens ambientais, identificando tais problemas na cidade, uma vez que, a educação atual, trabalha na perspectiva do local ao global, devido ser de fácil acessibilidade, melhor entendimento e participação assídua dos envolvidos, pois age diretamente em seu convívio.

\section{A Educação Ambiental e as Convergências no Espaço Urbano de Sobral}

Entende - se por educação ambiental, toda ação educativa que contribui para a formação de cidadãos conscientes, no que diz respeito, a preservação do meio ambiente e apto a tomar decisões coletivas sobre o mesmo, as quais, necessárias ao desenvolvimento de uma sociedade sustentável. 
Revista Nacional de

Gerenciamento de Cidades

Ainda nesta lógica, ressalta a lei de educação ambiental, a qual define - se mediante os processos pelos quais o indivíduo e a coletividade constroem valores sociais, conhecimentos, habilidades, atitudes e competências voltadas à conservação do meio ambiente, bem de uso comum do povo, essencial a uma sadia qualidade de vida e sua sustentabilidade.

Neste caso, de acordo com Leff (2001), existe uma dificuldade em resolvermos crescentes e complexos problemas ambientais, e reverter suas causas, sem que ocorra uma mudança radical nos sistemas de conhecimento, nos valores e nos comportamentos gerados pela dinâmica da racionalidade existente, fundada nos aspectos econômicos do desenvolvimento. Por isso, é de suma relevância abordar estas questões, constatemente na escola, esta, segundo Alarcão (2007), deve ser pensadora, flexível e atrativa, devido ser um local que influencia e é influenciada pela sociedade, características estas fundamentais para a construção de um mundo sustentável.

É importante ressaltar que a escola é um espaço valioso para a conscientização de crianças e adolescentes, podendo estes, tornar - se multiplicadores dos conhecimentos adquiridos e se engajarem na conscientização ambiental, com iniciativas nas comunidades que residem.

De acordo com MINC (2008), "nas salas de aula, a ecologia é tratada como um conjunto de conhecimentos científicos e informações sobre ciclos biológicos e ecossistemas, incluindo fauna, flora e cadeias alimentares, mas não é suficiente". É evidente que esses conhecimentos são imprescindíveis para a compreensão da vida no planeta, e ajuda a defender o meio ambiente, mas o que se necessita, é a utilização da educação ambiental como ferramenta política dentro da escola, começando com atitudes pequenas, ou seja, como colocar o lixo na lixeira, e em seguida, tais atitudes, ganharão proporções maiores, até adquirir consciência de qual ação praticar, para uma melhor convivência, não só com o meio em que vive, mas com as pessoas que estão ao seu redor, pois a educação ambiental não é só a relação homem versus natureza, mas também a do homem com ele mesmo. 


\section{Revista Nacional de}

Observando a cidade de Sobral, percebe - se que em suas periferias existe uma relação negativa entre pobreza e meio ambiente, devido suas localizações serem inadequadas para a população, isto é, em locais de encostas, próximos a ríos, entre outros, os quais contribuem para o aumento da devastação ambiental, bem como, a falta de incentivos da própria população em viver de forma harmônica com os recursos naturais. Desse modo, aquele local passa a representar sinais de sujeira e descaso.

Vale ressaltar ainda, que influenciados por uma sociedade que prioriza a estética, acabamos nos importando mais, com os locais que nao enfrentam tais desafios, e os que não se inserem nessa questão, são apenas recortes de uma cidade populosa. Reforçando assim, a concepção "sociedade de risco", de Beck (1992), a qual, amplia a compreensão de um cenário marcado por nova lógica de distribuição dos riscos.

Leonard (1992) diz que, a pobreza corrente e a destruição ambiental, bloqueiam o progresso econômico e social, além de interferir nas intervenções ambientais que buscam reduzir os efeitos sobre a pobreza trazendo benefícios ao meio ambiente.

Diante disso, o diagnóstico participativo serve como suporte para que mudanças aconteçam, isto é, pode - se levar os alunos aos locais identificados e discutidos em sala, para assim, ressaltar a importância da educação ambiental, primeiramente em seu cotidiano, buscando com isso, o melhor uso dos recursos naturais, na tentativa de melhorar o bem - estar social, seja em termos de qualidade de vida de seus cidadãos, na geração de emprego e de renda ou na atenção às questões ambientais, e assim, despertar nestes, uma necessidade de cuidado com o meio.

Neste sentido, entende - se, que a pobreza presente principalmente nas periferias urbanas, pode ser oriunda de problemas ambientais, como 0 desmatamento, a poluição do ar e o aquecimento global, entre outros. Assim, a melhoria das condições do meio ambiente, podem resultar em um progresso das 
Revista Nacional de

Gerenciamento de Cidades

condições econômicas e sociais, pois a reciclagem de resíduos, a conservação da água e da energía, são exemplos de como criar empregos e melhorar tanto a qualidade de vida da população, quanto a qualidade do meio ambiente.

Dentro desta lógica, a postura de dependência e falta de cuidado com o meio é oriunda, em geral, da desinformação, e de um déficit de práticas comunitárias, no que se refere a participação e envolvimento dos cidadãos, e que com isso, os mesmos possam propôr uma nova cultura de direitos, baseados na motivação e na co - participação da gestão ambiental.

Assim, de acordo com Carvalho (2008), a valorização da vida, a preocupação com as futuras gerações, o cuidado com o meio e o desenvolvimento de novas formas de pensar a realidade, são preocupações da Educação Ambiental e devem ser preponderantes no âmbito escolar.

\section{OBJETIVO}

Discutir sobre a importancia da educação ambiental no ensino Básico, através da inserção da comunidade escolar do Colégio Dom José Tupinambá da Frota, na perspectiva ambiental, enfatizando a cidade de Sobral - CE.

\section{METODOLOGIA}

A pesquisa coloca - se no sentido de fazer a relação do meio ambiente com a cidade, incentivando com a aprendizagem dos alunos e quais ações podem ser melhoradas em defesa da natureza, com a expectativa que o desenvolvimento de projetos contribua para a preservação ambiental.

O método adotado pautou - se na teoria e na prática. Para tanto, utilizou-se pesquisas em livros, revistas e sites para o suporte teórico transmitido em sala pelos docentes, bem como, discussões de cunho reflexivo acerca dos problemas existentes na cidade, além de palestras no auditório da referida escola com profissionais da área. 
Com relação à prática, os discentes motivados pela temática, arrecadaram uma quantidade significante de garrafas pets; participaram de oficinas de reciclagem de papel; construção de painéis, plantio de mudas, aulas práticas (lagoa da Fazenda, rio Acaraú, dentre outras). A partir das atividades realizadas, criou - se espaços para apresentações de trabalhos, danças, vídeos, poemas entre outras.

\title{
REFERENCIAL TEÓRICO
}

Diante dos problemas ambientais presente na cidade de Sobral, a respectiva escola, através de seus professores e materiais didáticos, buscou abordar de maneira didática e dinâmica tais discussões envolvendo de forma prática os discentes. Poderá promover ainda, um processo educativo junto aos professores que são capazes de desenvolver a educação, criar opiniões que podem realizar pequenas atitudes mediantes aos problemas ambientais, tornando essa prática cotidiana, poderá formar um alicerce para que seus alunos acreditem no seu potencial para combater os problemas mais próximos detectados, tomando uma atitude política, social e educativa que antes dessas informações poderiam ser desconhecidas. Para reforçar estas questões Minc (2008), afirma que:

\begin{abstract}
Ao longo dos tempos a percepção, o objeto e o ativismo na área ecológica foram se transformando. Da defesa das espécies animais e das florestas, o ambientalismo chegou aos sistemas produtivos, à vida urbana e passou a abranger questões como a saúde, as tecnologias, os direitos do consumidor e do cidadão. As escolas devem funcionar como pólos irradiadores de consciência ecológica, envolvendo as famílias e a comunidade. Escolas podem defender lagos, reflorestar encostas, abrigar centros de reciclagem. MINC (2008).
\end{abstract}

Desta maneira, entende - se que meio ambiente inclui todos os fatores que afetam diretamente o comportamento de um ser vivo ou de uma espécie incluindo a luz, o ar, a água, o solo e os próprios seres vivos, que coabitam no mesmo ambiente. Por isso, faz - se necessário ressaltar a sua dinâmica e as repercussões nas organizações sociais geradas pelo desenvolvimento de suas atividades. 


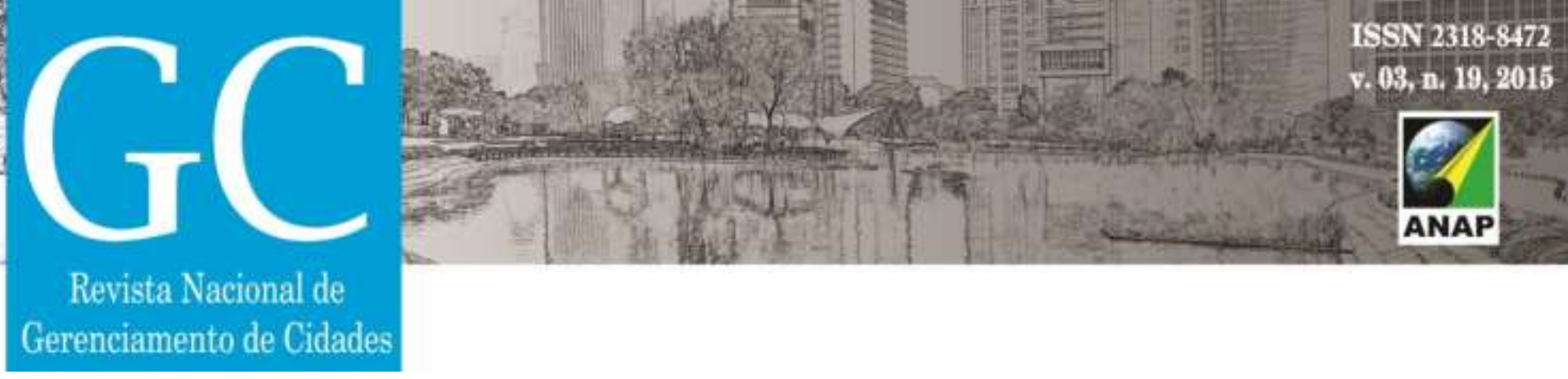

A sociedade como um todo é responsável pela preservação do meio ambiente, então, é preciso agir da melhor maneira possível para não modificá-lo de forma negativa, pois isso terá conseqüências para a qualidade de vida da atual e das futuras gerações, entendendo que:

O meio ambiente concebido, inicialmente, como as condições físicas e químicas, juntamente com os ecossistemas do mundo natural, e que constitui o habitat do homem, também é, por outro lado, uma realidade com dimensão do tempo e espaço. Essa realidade pode ser tanto histórica (do ponto de vista do processo de transformação dos aspectos estruturais e naturais desse meio pelo próprio homem, por causa de suas atividades) como social (na medida em que o homem vive e se organiza em sociedade, produzindo bens e serviços destinados a atender "as necessidades e sobrevivência de sua espécie (EMÍDIO apud, LIMA, 2007, p.127).

A educação ambiental constitui um processo ao mesmo tempo informativo e formativo dos indivíduos, tendo por objetivo a melhoria de sua qualidade de vida e a de todos os membros da comunidade a que pertencem. Fatores estes, baseados na legislação federal, que institui a Política Nacional de Educação Ambiental e define como educação "os processos por meio dos quais o individuo e a coletividade constrói valores sociais, conhecimentos, habilidades, atitudes e competências voltadas para a conservação do meio ambiente, bem de uso comum do povo, essencial à sadia qualidade de vida e sua sustentabilidade".

Ainda nesta perspectiva, no Artigo 225 da Constituição Federal existe a seguinte abordagem: Todos têm direito ao meio ambiente ecologicamente equilibrado, bem de uso comum do povo e essencial à qualidade de vida impondo se ao Poder público e à coletividade o dever de defendê-lo e preservá-lo para as presentes e futuras gerações. BRASIL (1988).

Diante disso, sabe - se que a sociedade humana não se sustenta sem água potável, ar puro, solo fértil e sem um clima ameno. Muitas pessoas, no entanto, ainda não compreenderam isso. Ao desenvolver suas atividades socioeconômicas, destroem de forma irracional as bases da sua própria sustentação. Não percebem que dependem de uma base ecológica para a sua vida e a de seus descendentes. Vivem como se fossem a última geração sobre a Terra. 


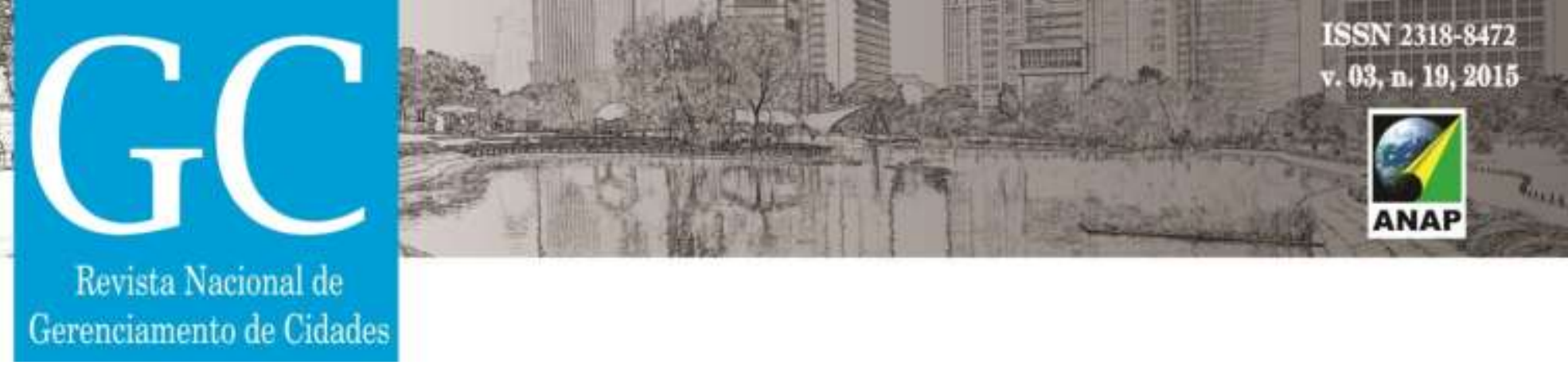

FIG 03 e 04: arrecadação de garrafas pets e mudas
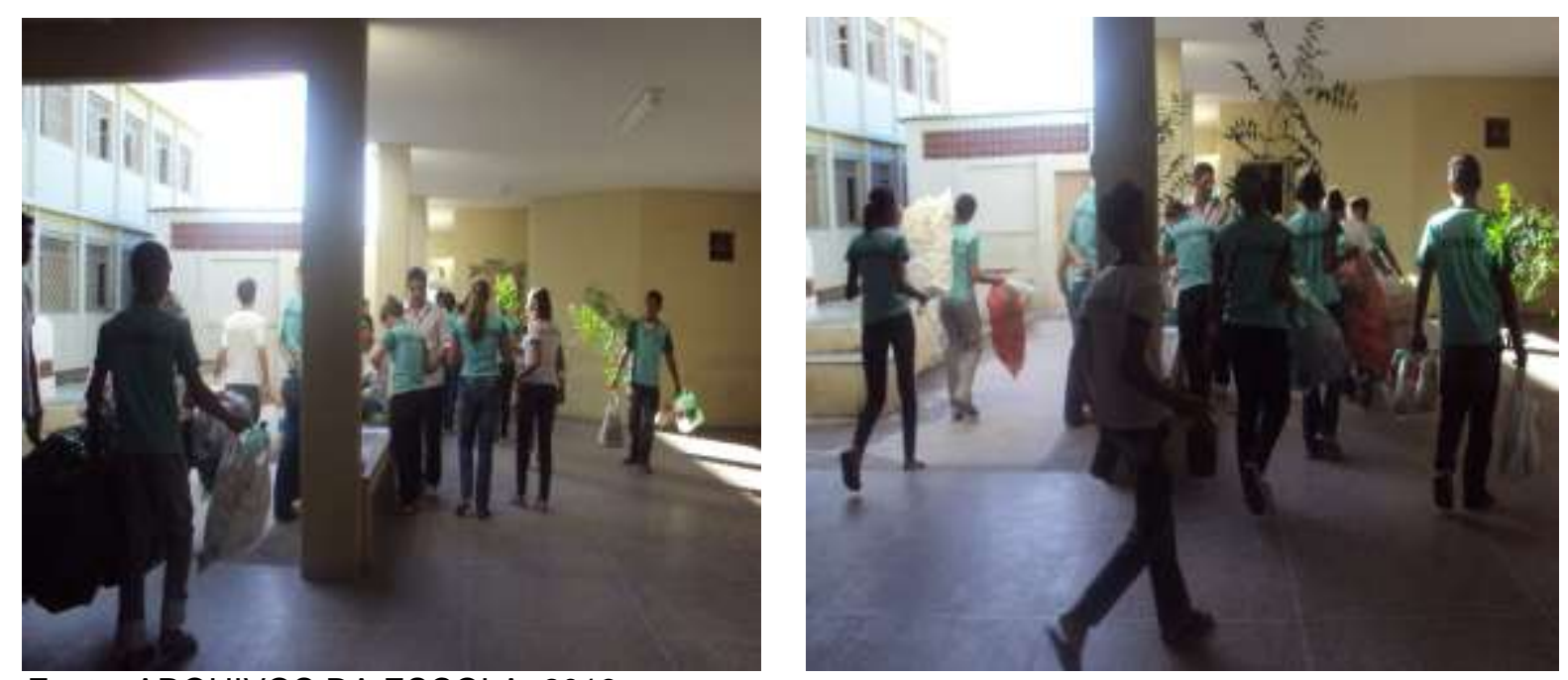

Fonte: ARQUIVOS DA ESCOLA, 2013.

As figuras (03 e 04) comprovam o envolvimento dos alunos, estes que se empenharam em arrecadar inúmeras garrafas pets com o intuito de doá - las para reciclagem, momento oportuno para aprender a confeccionar objetos derivantes das garrafas, através de oficinas de reciclagem.

FIGURAS 05 E 06: oficinas de reciclagem de papel.

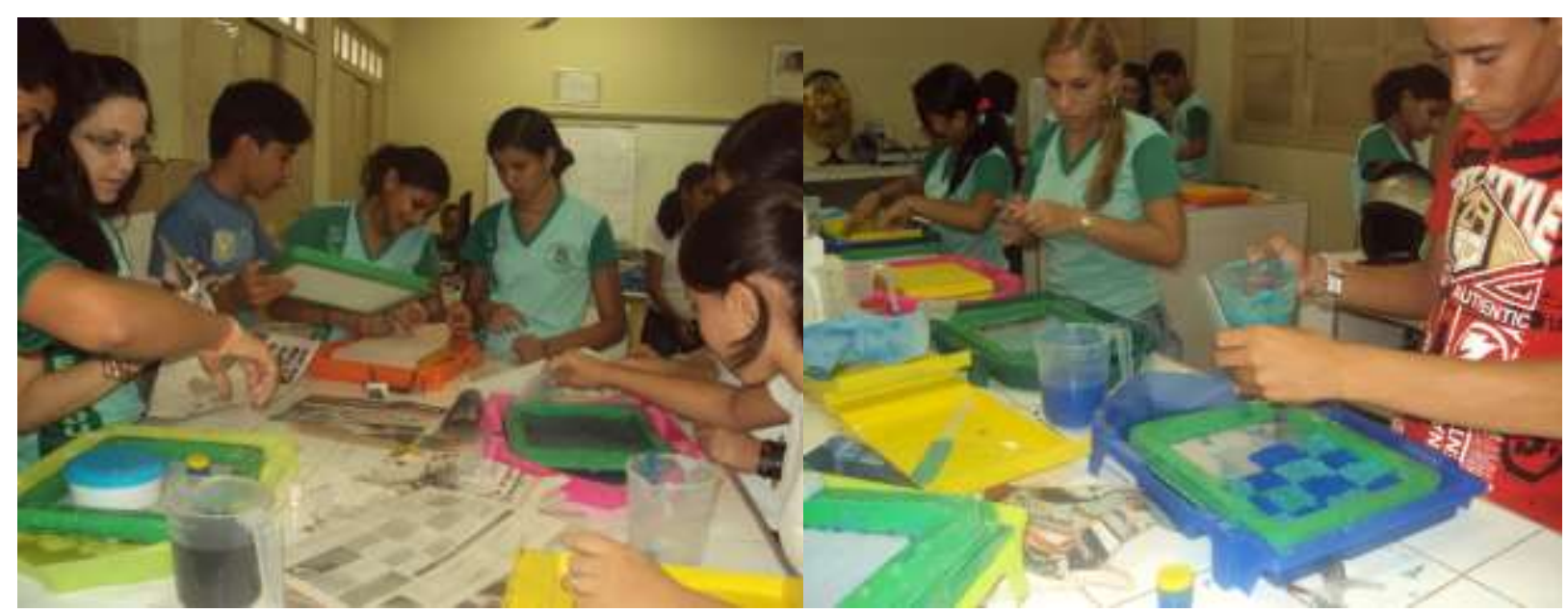

Fonte: ARQUIVOS DA ESCOLA, 2013. 


\section{Revista Nacional de}

\section{Gerenciamento de Cidades}

Tais atividades desenvolvidas na escola mostra a relevância de trabalhar com reciclagem, visto que, vários materiais descartáveis podem ser reutilizados (figuras 05 e 06). Além do incentivo a arborização, processo que influencia na diminuição da temperatura e no auxílio da biodiversidade, dentre outros fatores importantes à manutenção da natureza.

A partir da contextualização de Andrade (2006), a disseminação dos conhecimentos através de apresentações, facilita o entendimento dos conteúdos, estimula os participantes e aproxima a teoria da prática. Nesta lógica, fundamenta se na necessidade de avaliar o que vem sendo feito e transmitido sobre a educação ambiental e suas repercussões no cotidiano.

\section{CONCLUSÃO}

A escola dentro da Educação Ambiental deve sensibilizar o aluno a buscar valores que conduzam a uma convivência harmoniosa com o ambiente e as demais espécies que habitam o planeta, auxiliando - o a analisar criticamente os princípios que tem levado à destruição inconsequente dos recursos naturais e de várias espécies. Tendo a clareza que a natureza não é fonte inesgotável de recursos, suas reservas são finitas e devem ser utilizadas de maneira racional, evitando o desperdício, bem como, considerar a reciclagem, a arborização ou qualquer outra forma de cuidado, como processos vitais.

Vale salientar que o conhecimento teórico necessita ser associado à prática, e as aulas baseadas no currículo da escola, devem elencar as questões ambientais, e em seguida trabalhar na perspectiva de inserir os discentes em tal discussão a partir do seu cotidiano, como o que vem ocorrendo, ressaltadas pelas atividades desenvolvidas. Partindo desse pressuposto, contata - se que a referida escola desde sua criação tem uma preocupação com a comunidade, em particular, com a conscientização ambiental, reforçando sua importância alicerçada em seu slogan, tradição e credibilidade. 
Percebeu - se também, que mediante as ações desenvolvidas despertou nos discentes a vontade de cuidar da natureza, exigindo da escola medidas de preservação, como separação do lixo, arborização, evitar desperdício de água e de alimentos. Nota - se também, que estes, já começaram a mudar a visão com relação aos problemas ambientais na cidade, isto é, buscando conhecer as leis municipais e sua eficácia, bem como, sua atuação enquanto cidadão consciente e preocupado com o meio ambiente nos locais onde residem.

\section{REFERÊNCIAS BILIOGRÁFICAS}

ANDRADE, D. F. Implementação da Educação Ambiental em escolas: uma reflexão. In: Fundação Universidade Federal do Rio Grande. Revista Eletrônica do Mestrado em Educação Ambiental, v. 4.

BRASIL. Constituição (1988) Constituição da República Federativa do Brasil. Brasília: Senado, 2005.

CARVALHO, J. C. M. 1998. Em direção ao mundo da vida: interdisciplinaridade e educação ambiental. Sema \& Ipê, São Paulo, Brasil, 102pp.

DIAS, G. F. Educação Ambiental: princípios e práticas. São Paulo, Gaia, 1992.

GUERRA, R. T. GUSMÃO, C. R. C. A implantação da Educação Ambiental numa escola pública de Ensino Fundamental: teoria versus prática. João Pessoa, Anais do Encontro Paraibano de Educação Ambiental 2000 - Novos Tempos.

LIMA, Ana Marina Martins. Conceito de meio ambiente. disponível em: http://ambientedomeio.com/2011/032/5/conceito-de-meio-ambiente/. Acesso em 25 de março de 2011.

MINC, Carlos. Ecologia e cidadania / Carlos Minc. - 2. Ed. - São Paulo: Moderna, 2005. - (Coleção polêmica)

SOUZA, A. K. A relação escola-comunidade e a conservação ambiental. Monografia. João Pessoa, Universidade Federal da Paraíba, 2000

ANDRADE, Maria Margarida de. Introdução à metodologia científica: São Paulo: Editora Atlas, 2006.

BRASIL. Constituição (1988) Constituição da República Federativa do Brasil. Brasília: Senado, 2005.

SATO, M. Educação Ambiental. São Carlos. UFSCar/PP-ERN, 1995. 